\title{
Emotional Design for Games: A Framework for Player-Centric Approach in the Game Design Process
}

\author{
Shahrel Nizar Baharom ${ }^{1 *}$, Wee Hoe Tan ${ }^{2}$ and Mohammad Zaffwan Idris ${ }^{3}$ \\ ${ }^{1}$ Faculty of Art \& Design,Universiti Teknologi MARA (Perak), Malaysia \\ ${ }^{2}$ Education Research Laboratory, Sultan Idris Education University, \\ Malaysia \\ ${ }^{3}$ Faculty of Art, Computing \& Creative Industry, Sultan Idris Eductition \\ University,Malaysia \\ *Corresponding author: Shahrel Nizar Baharom(shahrelnizar@gmail.com) \\ Abstract
}

\begin{abstract}
This paper elaborates a conceptual framework of emotional design for games and explains how it could assist game designers in designing immersive games. Hlayer-centric approach is identified as the core of the framework which signifies the rotes of emotion in the game design process particularly at the pre-production stoge. Since emotion and perception are biological process of human beings, players are prone to choose digital games which offer immense pleasure and enjoyment experience. In game playing process, players are mostly dominated by perception which leads their behavidr to act. Perception is driven by immediate emotional response at visceral level. This phenomenot emerges from the integration between three domains of learning and three levels of emotional design. This integration would contribute to the establishment of study into playercentric emotional design for games.
\end{abstract}

Keywords: Emotion, Perception, Emotional design, Player-centric game design

\section{Introduction}

Digital games are conselered as hedonic products that necessitate players to play with emotional responses Jantasy conception and multi-sensory engrossment [1]. These three components are outcomes of designers' creative juice. In particular, emotional responses are intended immediate stimulation, generated for specific playing experience. In other words, designers would plan for every in-game events in order to determine players' emotion throughout the game playing experience, in which the design process is aligned and centered to players' attributes, hence the notion of playercentrio emotional design. The game design process has to be player-centric because players will only be interested in games that meet their needs and preferences [2]. To avoid creating games which are not interested or preferred by players, game designers should adopt or adapt to the player-centric design approach. As nowadays digital games primarily rely on players' desire to play, it is essential to explore how games could be designed to meet players' desire. In this sense, the exploration of the know-how would ideally be structured in a form of conceptual framework for designers to understand the multifaceted nature of emotion in design.

This paper presents and explains a conceptual framework of the player-centric emotional design for games. The framework connects Norman's three levels of emotional design [9] and Blooms' three domains of learning [10] to Prensky's six structural elements of games [21]. A broader sense of learning was adopted in the connection, in which the act of playing involves the acquisition of knowledge, skills 
and attitude within the game world. These three aspects of learning are regarded as cognitive, psychomotor and affective domains in the field of educational psychology. Each of these domains can be aligned to one level of emotional design when relating to how game elements could be designed to meet player's aesthetic, functional, sociopolitical and economic requirements in games (see Table 1). In this sense, the conceptual framework could be used by game designers to generate guiding principles when designing specific game elements or integrating several elements to form a game.

\section{Table 1. The Connection between Three Levels of Emotional Design and Three Domains of Learning in Relation to Six Structural Elements of Game}

\begin{tabular}{|c|c|c|}
\hline $\begin{array}{l}\text { Level of } \\
\text { emotional } \\
\text { design }\end{array}$ & Relation to the Structural Elements of Games & $\begin{array}{l}\text { Domains of } \\
\text { learning }\end{array}$ \\
\hline $\begin{array}{l}\text { Visceral } \\
\text { (Aesthetic) }\end{array}$ & $\begin{array}{l}\text { The emotional reflex towards the appearahces of } \\
\text { game elements. } \\
\text { The affective processing makes rapid judgement of } \\
\text { what is good or bad, safe or dangerous. } \\
\text { The automatic, prewired visceral level is } \\
\text { biologically determined. }\end{array}$ & $\begin{array}{l}\text { Affective } \\
\text { (Attitude) }\end{array}$ \\
\hline $\begin{array}{l}\text { Behavioural } \\
\text { (Functional) }\end{array}$ & $\begin{array}{l}\text { The pleasure towards the effectiveness of using } \\
\text { game elements. } \\
\text { The behavioural teyel contains the brain processes } \\
\text { that controlin-game behaviour }\end{array}$ & $\begin{array}{r}\text { Psychomotor } \\
\text { (skills) }\end{array}$ \\
\hline $\begin{array}{l}\text { Reflective } \\
\text { (Socio-political } \\
\& \text { economic) }\end{array}$ & $\begin{array}{l}\text { The rationalization andinfellectualization of game } \\
\text { elements } \\
\text { The refleetive thought does not have direct access } \\
\text { either to the sensbry input or to the control of } \\
\text { behaviour. }\end{array}$ & $\begin{array}{r}\text { Cognitive } \\
\text { (knowledge) }\end{array}$ \\
\hline
\end{tabular}

Among the learning domains, the players' affective responses in game playing process is an importan matter to designers and developers, because players are becoming more and more unpredictable when buying or consuming digital games [2]. Normally, the determinning purchasing factors remain mysterious until the end of an initial playing session [3]. Therefore, capturing their interest at the first sight is crucial, at least to enable a game to be considered as a potential game to purchase.

Meanuhile, players'enjoyment experience in game playing has been identified as a key success factor of digital games [4]. To reach an optimal enjoyment experience, players must be directed to arrive at a mental state called "flow". The flow state occurs when people are fully immersed into the enjoyment of game playing activity [5]. According to Grodal [6], digital game is a medium of "full experiential flow" which comprises emotion, perception and cognition of first-person actions. Therefore, game designers should be well-verse with the roles of emotion and perception in order to design an immersive player-centric experience. This player-centric design approach is a form of innovative game design that could hold players' emotional engagement throughout the game playing experience [7]. The approach would meet an infinite combination of players' emotional and perceptual needs, and subsequently enhances the originality and variety of commercial games [8]. In brief, understanding the roles of emotion and perception is essential for designing immersive games which could direct players to enter the flow state, and eventually purchase the game as first-time players. 
The explanation of the conceptual framework in this paper begins with an overview of the concepts of emotion, perception, and reason, and how both concepts play significant roles in games-setting the ground for the framework. The framework contains other key concepts associated to player-centric game design approach, covering three levels of emotional design, which correspond to three domains of learning. This in turn, would facilitate game designers to generate guidelines for designing games. The use of the guidelines would enable designers to operationalize ideas into specific player-centered design tasks which are associated to each game element [11].

\section{The Gist of Emotion, Perception and Reason}

In psychological research, emotion works as a resolution that differentiates what people do and feel towards events and environment where the people are situated. Based on this proposition, emotion distinguishes hom people may relact in different ways to the same situation on different occasions [12]. In this sense, emotion is associated to three ranges of psychological phenomena, i.e. feelings, behaviors and bodily reaction. These phenomena are outcomes of human capability when interacting with sensory stimuli generated from the events or environment the human encounters [13].To understand the mechanism behin the interaction, one has to comprehend the formation of habit, voluntary actions sensory impressions and thought [14]. The understanding of the mechanism will lead to the rationalization of psychological concepts like pleasure and pain, e Ealuation, prority of control, preferences and desires [14]. The psychological connection between emotion and the above mentioned concepts revealed the function of emotion as a way of knowing in the theory of knowledge or epistemology.

The function of emotion as a way of knowing can also be examined from the biological perspective in biology emotion is formed when sensory data is processed through the hippocampus or "Nizard brain", and then disseminating to other centres of the brain, including those involving reason. A form of neurochemical substance will trigger the brain centres which transform human thought, perception, decision making and behavior [9]. Hence, emotion is influencing the other ways of knowing, including intuition, reason and sense of perception [15]. In the context of game design, in-game events and environment could be carefully designed to evoke emotion, in order to influence players' intuition, reason and sense of perception in the game world.

The brain system processes information through the affective, psychomotor and cognitive sub-systems or layers. The affective layer involves rapid and immediate judgement made in response to stimulant encountered in all kinds of conditions; the psychonotor layer processess and controls human behaviours; while the cognitive layer involves comprehension and interpretation of stimuli and conditions [10]. In the context of playing games with fast-pace physical coordination challenges, players' actionsare based on the outcomes affective and behavioural layers. However, when they are playing games which challenge their strategic thinking or reasoning skills, their ingame actions would be mainly directed by the cognitive layer.This differentiation in brain system leads psychologists like Norman [9] to divide emotion into three different levels of the brain, i.e. visceral, behavioural and reflective levels. The differentiation is in line with the delienation of three domains of learning, i.e. affective, psychomotor and cognitive domains [10]. 
In educational psychology, perception is the first level of skills in the psychomotor domain of learning [19]. It represents "the ability to use sensory cues to guide motor activity", ranging "from sensory stimulation, through cue selection, to translation" [19]. This definition is parallel to the role of behavioral level in the emotional design [9]. The psychomotor domain is comprised of utilizing motor skills and coordinating people to detect non verbal-communication cues i.e. to choose, describe, detect and differentiate their behavior for further pace of action to be taken [19].

Perception is also an active process that enables human to sample information and sensation from specific environment decisively [17]. It may embark human intelligence to make a decision, e.g., whether to pursue something or not. The five human'sensessight, hearing, smell, touch and taste-work collectively as an active sensor to sample human behavior through five perceptual systems, which are looking (vision), Mistening (auditory), touching (haptic), smelling (olfactory), and tasting (gus atory). In brief, perception is guided by human senses, controlling human behaviors to accomplish goals and purposes in life [18].The functions of emotion and perception should encompass the intersection that both elements areconnected to biological process of the human brain (see Figure 1).

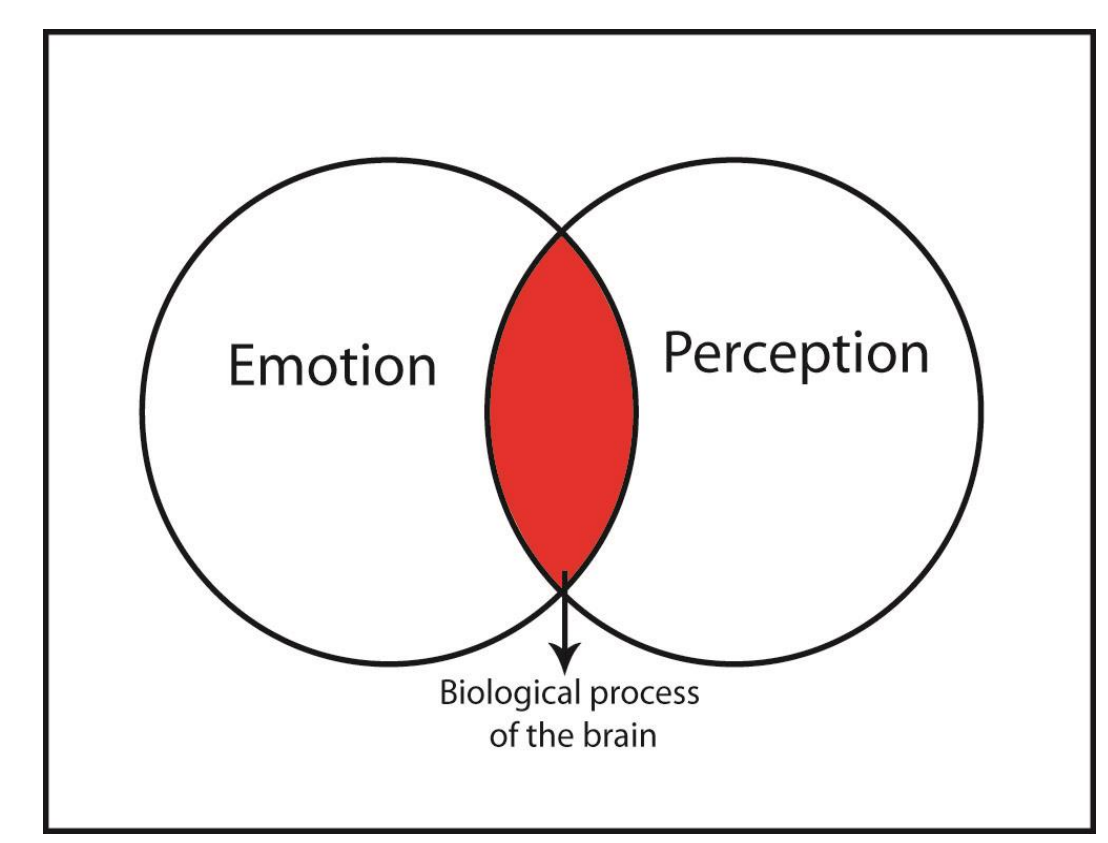

Figure 1. Intersection between Emotion and Perception

In player-centric game design, the roles of emotion and perception are contributing to the design and development of the six structural elements in games [20]. These elements include goal, feedback, rules, interaction, narrative and challenge [21]. When playing games, players' emotion is aroused to attain game goals, take challenges, abide game rules, interact with the game world or other players, react to feedback, and understands game narrative. The arousal would be perceived through at least one sensory receptor, which would prompt player's behavior in the forms of action or reaction. In Table 2, shows how both elements are functioning towards the six elements in the game structure. 


\section{Table 2. The Roles of Emotion and Perception in Six Structural Elements of} Game

\begin{tabular}{|c|c|c|c|}
\hline & & Roles of emotion & Roles of perception \\
\hline \multirow[t]{6}{*}{$\begin{array}{l}\text { Structural } \\
\text { Elements of } \\
\text { Game }\end{array}$} & Goal & $\begin{array}{l}\text { Goal arouses player's emotion } \\
\text { to be directed in achieving } \\
\text { game goals and subsidiary } \\
\text { missions. }\end{array}$ & $\begin{array}{l}\text { Player identifies and relates sensory } \\
\text { cues in the game world to } \\
\text { accomplish missions and to achieve } \\
\text { game goal. }\end{array}$ \\
\hline & Feedback & $\begin{array}{l}\text { Feedback arouses player's } \\
\text { emotion to learn dearly from } \\
\text { in-game events and situations. }\end{array}$ & $\begin{array}{l}\text { Player detects and reacts upon in- } \\
\text { game feedback to try out the } \\
\text { usefulness of a strategy, tactic or } \\
\text { movement. }\end{array}$ \\
\hline & Rules & $\begin{array}{l}\text { Rules stimulate player's } \\
\text { emotion in strategizing in- } \\
\text { game behaviors and actions } \\
\text { while abiding rules. }\end{array}$ & $\begin{array}{l}\text { Player detects and relates rules to } \\
\text { the game goal to overcome } \\
\text { challenges. }\end{array}$ \\
\hline & Interaction & $\begin{array}{l}\text { Interaction stimulates player's } \\
\text { emotion to engage with other } \\
\text { players and in-game situation } \\
\text { tactically or strategically. }\end{array}$ & $\begin{array}{l}\text { Player detects the type and nature of } \\
\text { specific interaction to distinguish } \\
\text { friends and enemies, safe and } \\
\text { danger in the game world. }\end{array}$ \\
\hline & Narrative & $\begin{array}{l}\text { Narrative arouses player's } \\
\text { emotion to transcend avatar he } \\
\text { or she controlsin the game } \\
\text { world. }\end{array}$ & $\begin{array}{l}\text { Player describes the storyline in the } \\
\text { game world by relating narrative to } \\
\text { other game elements. }\end{array}$ \\
\hline & Challenge & $\begin{array}{l}\text { Challepges stimulate player's } \\
\text { emotion to confront and } \\
\text { overcome in-game challenges } \\
\text { norder to achieve game goal. }\end{array}$ & $\begin{array}{l}\text { Player detects and relates challenges } \\
\text { to the game narrative and the } \\
\text { attainment of missions and goal. }\end{array}$ \\
\hline
\end{tabular}

In the theory of knowledge, reaśon is the most common way we use to make sense of things. It is connected to the oggnitive domain learning and the reflective layer of emotional design. Reason works as specialized machinery in the brain to make sense and translate the information captured by human beings. The captured information is decoded into language which will trigger the brain to refine decoded information into neural "descriptions" to initiate specific human behavior towards stimulations of objects and events in all kinds of conditions. Some of the interaction is immediate reaction while others allow human to organize actions deliberately upon particular objects and events [16]. Although this paper focuses on the roles of emotion and perception, the importance of reason is not neglected, and it has been included in the proposed conceptual framework.

\section{Related Studies on Emotion and Perception in Game Design}

In game design perspective, emotion is identified as an agent to cultivate players' enjoyable experience and engagement in game playing activity [22]. This leads to the creation of the '4Keys2 Fun' model, which is meant for increasing players' engagement with games [22]. The first key is hard fun, focusing on players' actions to deploy strategies, avoid obstacles and achieve goals which involve frustration, personal triumph and relief. The second key is easy fun, prompting players' curiosity and imagination through exploration, fantasy and creativity in the game world. The third key is serious fun, stimulating players' action to collect things, repeat movement, and 
follow rhythm. The last key is the people fun, amusing players to communicate, compete or cooperate with other players inside or outside the game world [23].

When the term 'emotioneering' was coined, emotion was induced in games through game story akin to producing a film for entertainment [24]. The game world in the story was enriched with meaningful and emotion-rich experiences [24]. The concept of 'emotioneering' was established based on 300 different techniques. For instance, the 'first-person deepening technique' was deployed in the game which acquired players to act decisively - to shoot or not to shoot a target, in which players' emotion was evoked when confronting difficult choices.

Perception studies in games are related to players' bodily reaction upon sensory cues presented to them in game playing session. Although playing in the game world environment is a subset of reality, players' imagination could become a foundation for creating a desirable digital games [25]. Players are abiding the reality rules set in games which make them experience the fictional game environment. For instance, players ought to abide specific rules while slaying a fictional dragon [26].

Players' perceptions in games are related to their experience in real life [27]. Thus, playing games allows players to become superior in the game World where they can take physical or virtual actions to achieve game goals. The game playing experience includes iterative feedback that links the real body and the virtual game world to embark realism in games. The notion of realism in games is about body-subjective, which is not meant for realistic presentation; instea it is meant for players' action. In the game design perspective, perception playss an important role in shaping players' behaviors in game playing activity which are driven solely by emotion [28].

\section{Issues of Player-centric in the Game Design Process}

Game is an art form which grants designers the right to design games based on their own idea and creativity. Most of the game designers rely primarily on their personal perspective when designing games, as opposed to the demand or trend in the commercial game market [29]. Nonetheless, game designers should take the desires or needs of players into consideration, if the design would be intended for making a meaningful game experience and outcomes [30]. The players' experience in games is relatively close to the emotional response that is imminent to fun-an important aspect of game playing which players expect to obtain from games [31]. By considering players' desires or'needs in every game development stage, designers and developers would be able to produce successful digital games [11].

In brief the game design process involves concept design pre-production, production and post production [32]. Referring to the game production, the concept design stage is mergng with the pre-production stage since both stages are significant to the initial plan for the game designer to design games [33]. The production stage contains the game development based on the rationalization of the design works in the preproduction stage which engross the programming works that make the game content alive with characters realism in games, sensible visual appearance, level design route and vindicated game mission with the support of AI system. This task involves programmers to support the creative groups such as game designers, level designers, animators and many more. The post-production is mainly functioning on the final testing and deployment, followed by the task of sales and marketing people and distributors to dispense the completion of digital games into the market [7, 34]. 
From the perspective of player-centric approach, the best practice is to involves players in the early stage of game design explicitly in pre-production stage [35]. Adams [36] has supported the player-centric game design at an early stage by branching the game design process into three iterative stages; concept, elaboration and tuning collectively with the suggested tools and methods. However, in the current practice of player-centric approach is not parallel to the best practice since the players' experience only involve in the final stage for game testing purposes. It will jeopardize the efficiency of player-centric approach which the end results are indecisive and creates the predicament for game publishers or game developers if the final test shows negative results [37].

User-centered game design [38] has been highlighted as a reliable method for user evaluation and user testing of games. Yet, the implementation of this testing method is working at the end of the game design process. The next rational pace i to start the user research evaluation and testing at the beginning of the design process which the good game design must start with the user's needs in their natural setting [39].

\section{Player-centric Approach in the Emotional Design Model for Games}

The player-centric approach plays a significant contribution in the development of Emotional Design Model for Games. In games, players are mostly dominated by perception which lead their behavior response and it drives by the immediate emotional response through visceral level [20]. The framework is mainly an adaptation of emotional design concept by Norman [9] whichenerged from the integration of three learning domain (cognitive, affective and psychómotor) and three levels of human brain processing (visceral, behavioral and reflective) which illustrated in Egure 2. The reason for choosing the learning domain in educational psychology [40] is to establish learning as a continuous process of human development âna relatively connected to game playing process[41]. In addition, games are a subset of both play and fun which embrace the players' learning process [21].

In brief, the affective domain involves people's emotional process and attitude which corresponds to the roles olemotion on a visceral level perspective of the brain. The psychomotor domain which comprises of utilizing motor-skills and people's coordination are suitable in corresponding to the roles of perception which fall under the behavior lever that contains the brain process that control everyday behavior. The cognitive domain is signifying to the development of people's mental skills and the acquisition of knowledge which corresponds to the reflective level. This part mainly involves in the intellectual process of the brain. 


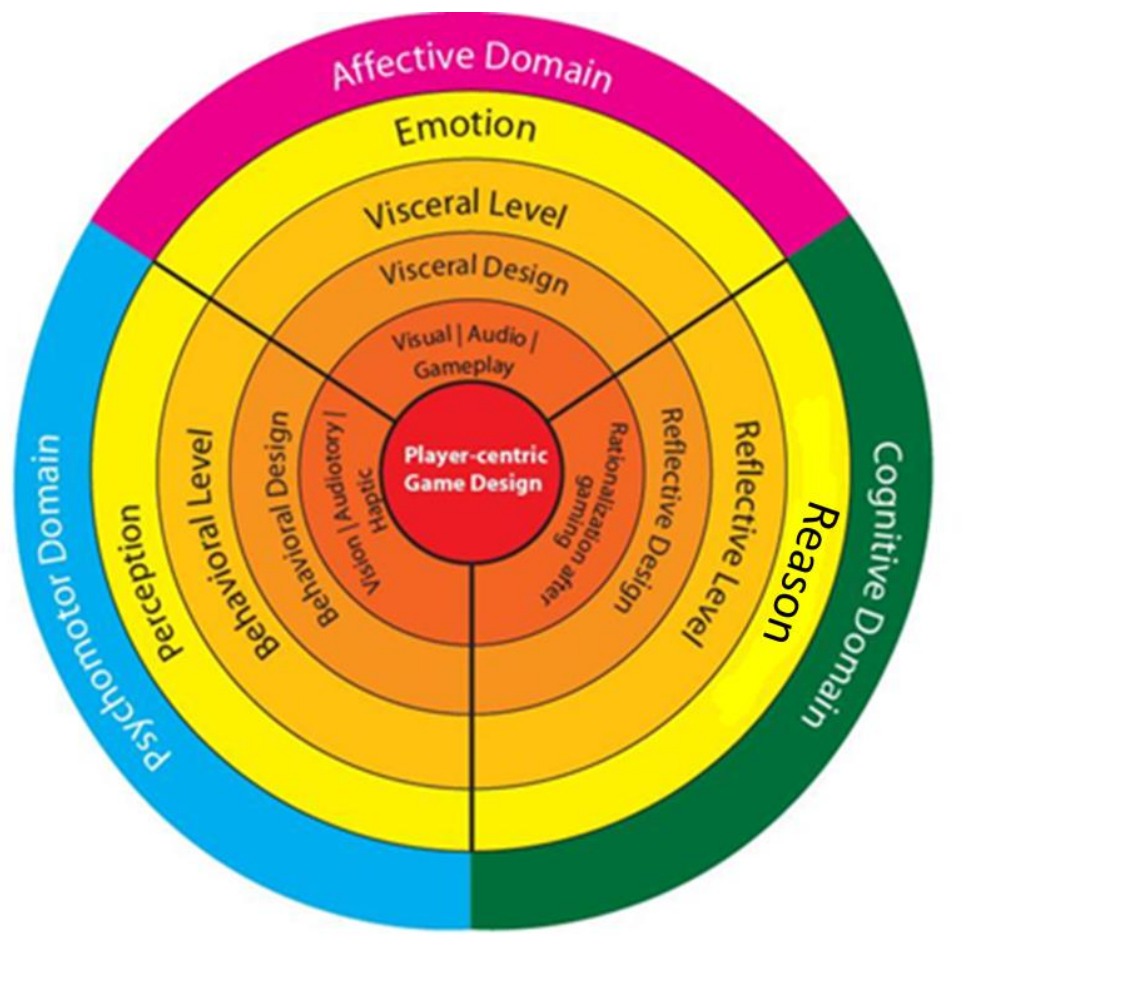

Figure 2. A Conceptual Framework of Emotional Design for Games

In the process of designing games game designers should emphasize on players' emotional design of viseeral level through their physical features such as look, feel and sound [9]. The implementation of visceral level of design is compulsory for the appearance of games which divided by three major categories such as visual (aesthetic components such as animation, interface design, character design and storyline), audio (music and sfx) and gameplay) (game control and game mechanics).

In behavior level, game designers should aware of players' usability in games by focusing to the perception of players. Perception will guide players to use their psychomotor skill to perform well in games. The behavior design would assist game designers to design games through players' vision, auditory and touch (haptic) which lead them to perceived usability in game playing process.

In refleative level, players will control their pleasure due to intellectual ability for further feflection towards games. This process is mostly activated after the game playing activity has come to the end and players might use their most cognitive abilities to rationalize games [42]. This will embarks an opportunity to game designers for implementing reflective design for players' pride and ownership towards games [43].

\section{Conclusion and Future Works}

In emphasizing the player-centric game design approach by considering players' emotion and perception, game designers should identify the best practice in designing games through the human's biological process. The integration of learning domain and emotional design concept have emerged a conceptual framework that allows the creation of desirable digital games. However, this framework of emotional design for games has limited to involve players' reaction in game playing session which not to tap into a 
reflection level that requires players rationalization after concluding the game playing session.

As emotion and perception can be designed and measured, researchers are planning to create the special instrument to facilitate game designers in designing games based on emotion and perception of players at an early design stage (Pre-production stage). This is to ensure the game design process will meet the purposes and less risk of failure. The future works will begin by refining the scope of study on a visceral level of emotional design in the game design field.

\section{Acknowledgements}

This paper is developed and expanded based on a conference paper, titled Emotional Design for Games: The Roles of Emotion and Perception in Game Design Process'. The paper was presented at the 1st International Symposium on Simulation and Serious Games in South Korea on 23 May 2014. This paper is an output of a research funded by Universiti Teknologi MARA (UiTM) and Malaysian Ministry of Education since 2013.

\section{References}

[1] A. Marchand and T. Hennig-Thurau, "Value Creation in the Video Game Industry: Industry Economics, Consumer Benefits, and Research Opportunities" J. Interact. Mark., yol. 27, no. 3, (2013), pp. 141-157.

[2] E. Hudlicka, "Affective computing for game désign", in Proceedings of the 4th Intl. North American Conference on Intelligent Games and Simulation (GAMEON NA) (2008), pp. 5-12.

[3] R. Hunicke, M. Leblanc, and R. Zubek, "MDA: A Fornal spproach to Game Design and Game Research", Discovery, vol. 83, no. 3, (2004), pp 04-04.

[4] P. Sweetser and P. Wyeth, "GameFlow: a modeffor evaluating player enjoyment in games", Comput. Entertain., vol. 3, no. 3, (2005),pp. 1-24.

[5] M. Csikszentmihalyi, "Flove The psychology of optimal experience", New York: HarperPerennial (1991).

[6] T. Grodal, "Stories for the eye, ear, and muscles: Video games, media, and embodied experiences", in The video game theory reader, (2003), pp, 129-155.

[7] T. Fullerton, "Game Design Workshop: A)Playcentric Approach to Creating Innovative Games", Second Edi. Morgan Kau mann publications, (2008).

[8] L. Ermi and F Mäyrä, "Player-Centred Game Design: Experiences in Using Scenario Study to Inform Mobile Game Design", Game Stud., vol. 5, (2005), pp. 1-12.

[9] D. A. Norman, "Emotional design", New York: Basic Books (2004).

[10] B. S. Bloom, M. D Englehard, E. J. Furst, W. H. Hill, and D. R. Krathwohl, "Taxonomy of educational objectives: The classification of educational goals: Handbook I", cognitive domain, vol. 16, (1956), pp. 207.

[11] J. Sykes and M. Federoff, "Player-centred game design", in Conference on Human Factors in Computing Systems, (2006). pp. 1731-1734.

[12] N. H. Frijda, "The emotions", Edited K.Dunlap, Cambridge University Press (1986) pp. 564.

[13] W. James, "What is an Emotion?", Mind, vol. 9, (1884), pp. 188-205.

[14] N. H. Erijda, "The Psychologists' Point of View", in Handbook of emotions, (2000), pp. xvi, 720.

[15] C. P. Henly, "Theory of Knowledge", in Proceeding of IBA Regional, (2012).

[16] R. Blake and R. Sekuler, "Perception", Fifth Edit. New York: McGraw Hill (2006).

[17] L. Carmichael and J. J. Gibson, "Introduction, in The Senses Considered as Perceptual Systems", (1966) pp. 1-6.

[18] J. S. Bruner and C. C. Goodman, "Value and need as organizing factors in perception", J. Abnorm. Psychol., vol. 42, (1947), pp. 33-44.

[19] E. J. Simpson, "The Classification of Educational Objectives in the Psychomotor Domain", vol. 3., pp. 43-56 (1972).

[20] B. Shahrel Nizar, W. H. Tan and Z. F. Muhammad, "Emotional Design for Games: The Roles of Emotion and Perception in Game Design Process", in 1st International Symposium on Simulation \& Serious Games, (2014) May 23-24, Ilsan, Korea.

[21] M. Prensky, "Digital Game-Based Learning", Minnesota: Paragon House, (2007).

[22] N. Lazzaro, "Why We Play Games: Four Keys to More Emotion Without Story", in Game Developers Conference,(2004), pp. 1-8. 
[23] N. Lazzaro, "The Four Fun Keys," in Game Usability: Advice from the Experts for Advancing the Player Experience, (2008), pp. 317-343.

[24] D. Freeman, "Creating emotion in games," in Computers in Entertainment, (2004), vol. 2, p. 15.

[25] C. Crawford, "The Art Game Design," Epilepsy Res., vol. 49, (2008), p. 512.

[26] J. Juul, "Video games between real rules and fictional worlds", MIT Press (2005).

[27] H. Sommerseth, Gamic realism: Player, perception and action in video game play,Proceedings of DiGRA 2007 Conference,(2007), pp. 765-768.

[28] E. Shinkle, "Video games, emotion and the six senses", Media, Cult. Soc., vol. 30, no. 6, (2008), pp. 907915.

[29] O. Sotamaa, "Perceptions of Player in Game Design Literature, in Situated Play", Proceedings of DiGRA 2007 Conference, (2007) pp. 456-465.

[30] B. Brathwaite and I. Schreiber, "Challenges for Game Designers: non digital exercises for game designers", Boston: Course Technology, (2009).

[31] R. Bartle, "Designing Virtual Worlds", Indianapolis: New Riders Publishing, (2004).

[32] A. Kerr, "Digital Games as Cultural Industry", in The Business and Culture of Digital Games: Gamework and Gameplay, London: SAGE Publications Ltd (2006).

[33] H. M. Chandler, "The Game Production Handbook Second Edition", Jones and Bartlett Publishers, LLC (2010).

[34] Game Development Process,(2011), [Online]. Available: http://Www.gamesoféxperience.com/2011/02/gamedevelopment-process/. [Accessed: 06-May-2014].

[35] A. Kerr, "Representing users in the design of digital games", in Proceedings of Computer Games and Digital Cultures Conference, (2002), pp. 277-295.

[36] E. Adams, "Fundamentals of Game Design", Second edi. New Riderst(2010).

[37] J. Vita, "Users as Co-creators: Player-centrio Game Design User Experience Magazine, User Experience, (2014)", [Online]. Available: http://www.usabilityprofessionals.org/uxmagazine/users-as-co-creators/. [Accessed: 12-Apr-2014].

[38] R. J. Pagulayan, K. Keeker, D. Wixon, R. L. Romero, and T. Fuller, "User-centered design in games, in Design", vol. 28, no. 4, J. A. Jackg and A sears, Eds. Lawrence Erlbaum Associates, (2003), pp. 883-906.

[39] V. A. Vanden Abeele and V. Van Rompaey, "Introducing human-centered research to game design: designing game concepts for and with senior citizens," in Proceedings of ACM CHI 2006 Conference on Human Factors in Computing Systems, (2006), vol. 2, pp. 1469-1474.

[40] L. W. Anderson and D. R. Krathwohl, "K taxonomy for learning, teaching, and assessing: A revision of Bloom's taxonomy of edtucational objectives, (2001).

[41] K. R. Ginsburg, "The Importance of play in promoting healthy child development and maintaining strong parent-child bondst Pediatrics, vol 119, (2007), pp. 182-191.

[42] T. Saethang and C. C. Kee, "A ganing strategy for teaching the use of critical cardiovascular drugs", J. Contin. Educ. Nurs., vol. 29 rø. 2, (1998), pp. 61-5.

[43] D. A. Norman and A. Ortony, "Designers and Users: Two Perspectives on Emotion and Design", in Symposium on Foundations of Interaction Design, (2003), pp. 1-13.

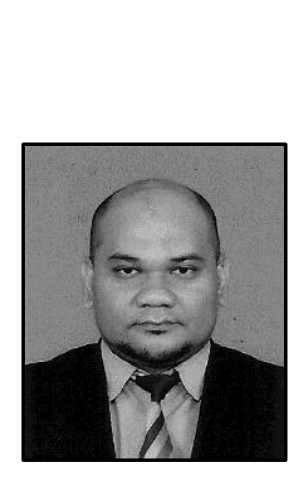

\section{Authors}

Shahrel Nizar Baharom, he holds aMaster of Arts in Visual Communication and New Mediafrom Universiti Teknologi MARA (UiTM), Malaysia. He has 14 years of teaching experience in various areas in graphic design, including advertising, illustration and multimedia. Currently, he is a doctoral researcher at the Sultan Idris Educational University (UPSI) with a full scholarship given by Ministry of Education, Malaysia and UiTM. His recent research interest is in game design, primarily in the area of emotional design for games. 


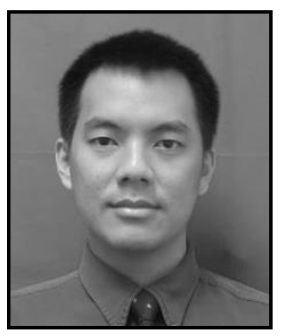

Wee Hoe Tan, he is the Deputy Director of Education Research Laboratory, Sultan Idris Education University. After the completion of a doctorate degree in game-based learning from University of Warwick in 2011, he began working between the creative industry and the academia, facilitating university-industry collaboration in Malaysia, UK and US. His research interests spread across various fields in creative multimedia and inventive problem solving.

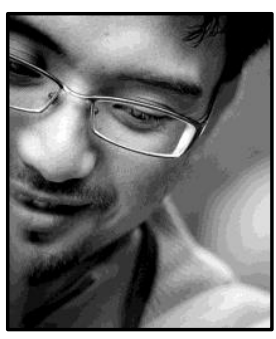

Muhammad Zaffwan Idris, he is a senior lecturer at Unizersiti Pendidikan Sultan Idris, a Malaysian public university located in Tanjong Malim. He received his Doctoral certificate from Swifburne University of Technology, Melbourne in 2011 His thesis entitred 'Branding in Higher Education: Testing the effectiveness of corporate visual identity'. Since then, his research interest has expended into other related areas within the scope of creative industry such as animation, games and integrated media.

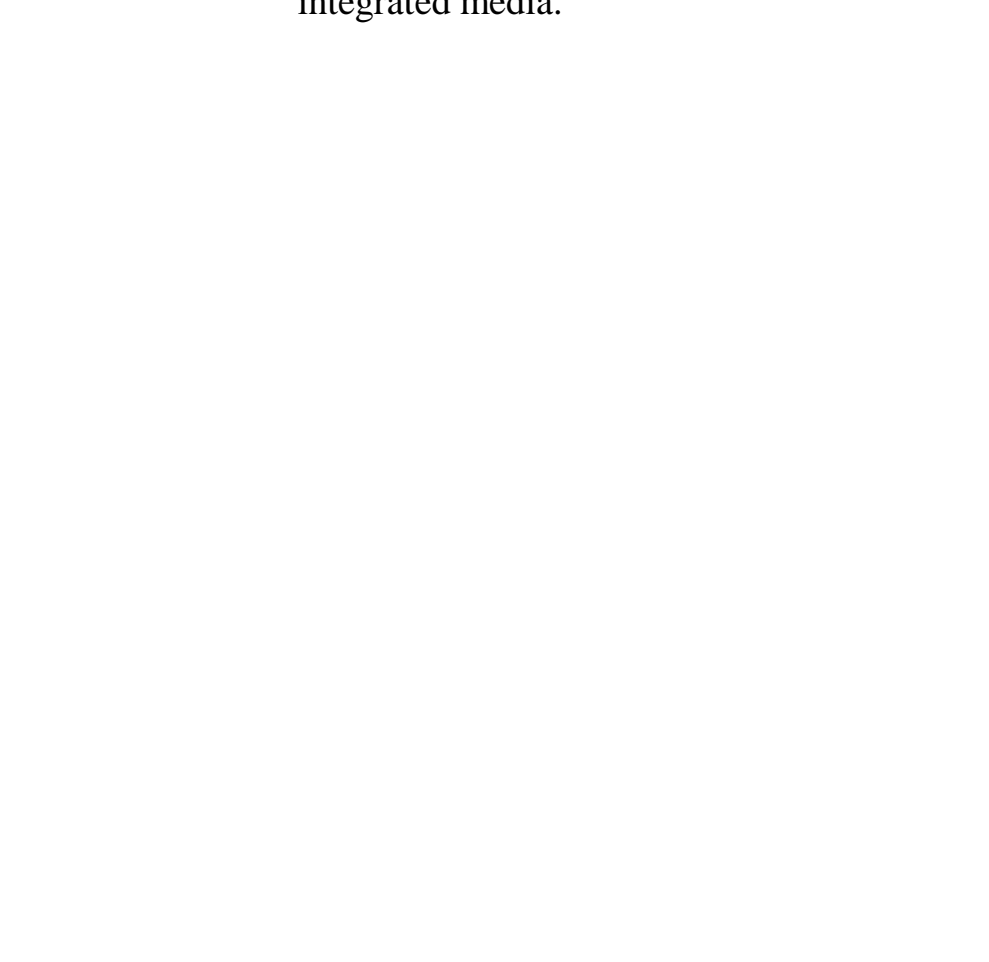


International Journal of Multimedia and Ubiquitous Engineering Vol. 9, No. 10 (2014)

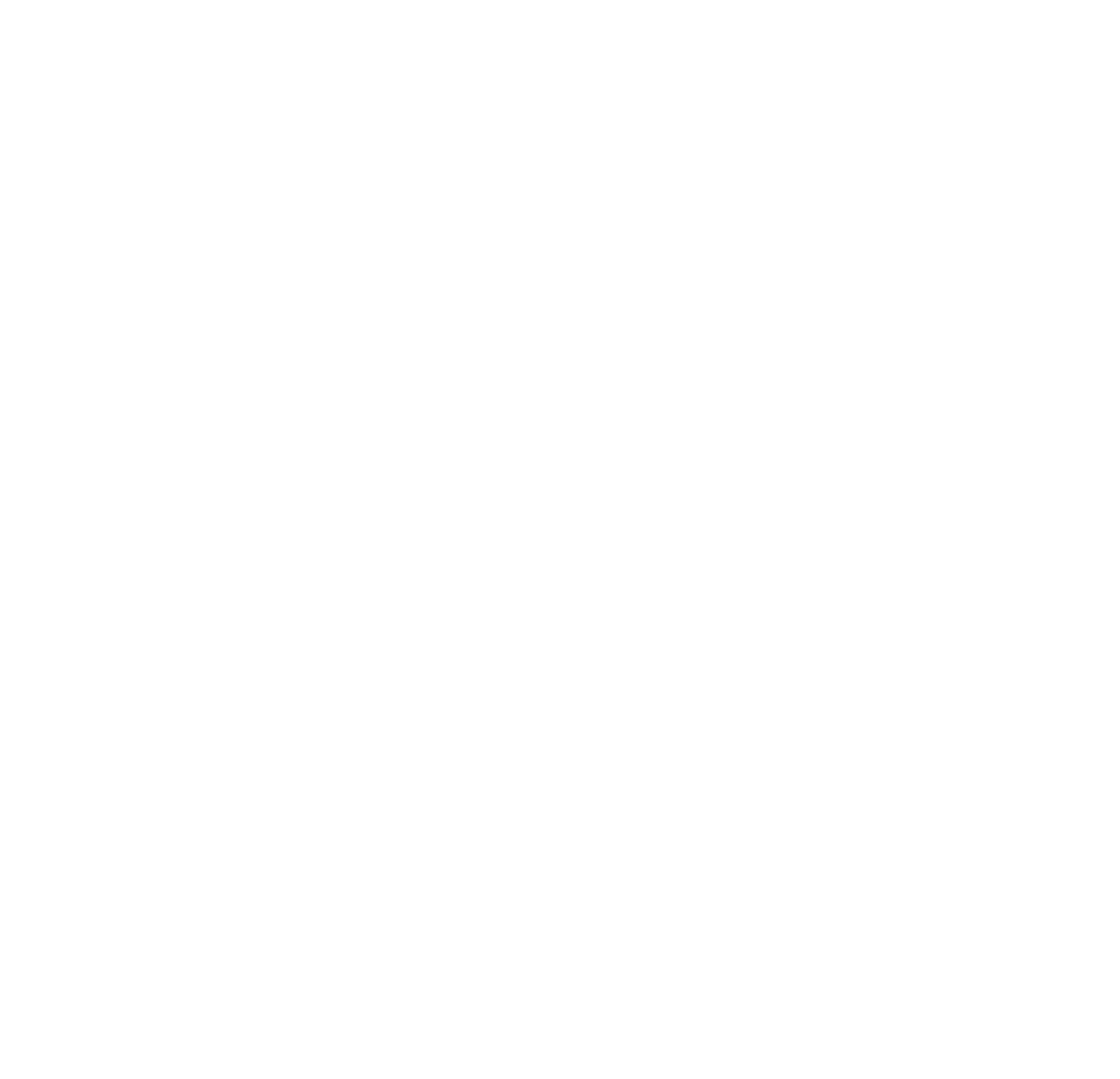

